\title{
Expression of Cytokeratin 6 and 16 in Middle Ear Cholesteatoma
}

\author{
Jacky Munilson $^{1 *}$ (D) Yan Edward $^{1} \mathbb{D}$, Lorensia Fitra Dwita ${ }^{1}$ D , Hirowati Ali $^{2}$ (D) \\ ${ }^{1}$ Department of Otorhinolaryngology, Faculty of Medicine, Andalas University, Padang, Indonesia; ${ }^{2}$ Department of Biochemistry, \\ Faculty of Biomedics, Andalas University, Padang, Indonesia
}

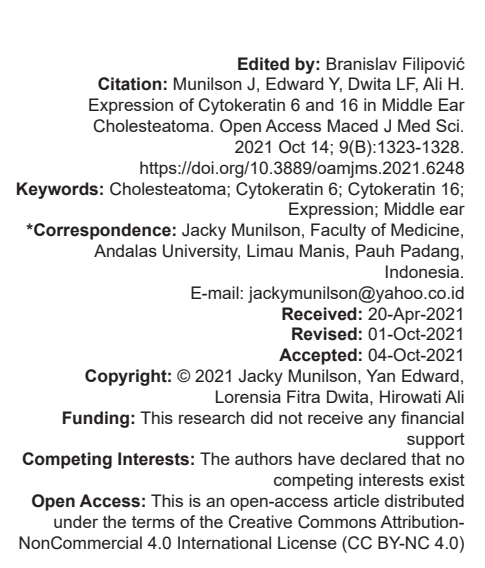

\section{Abstract}

BACKGROUND: Cholesteatoma is hyperproliferative because of the response of direct biomechanical trauma, and inflammation processes then lead to temporal bone destruction with some clinical manifestations of complications. The hyperproliferation mechanism occurred because of the activation of intermediate filament protein type I and type II known as cytokeratin (CK).

AIM: This study aimed to examine the expression CK 6 and CK 16 in cholesteatoma.

METHODS: This is a cross-sectional comparative study. Cholesteatoma specimens obtained from 15 patients who underwent surgery were considered as the case, and 15 normal retro-auricular skins were considered as the control. All samples were examined for expression through immunohistochemistry and scored using the immunoreactivity score. Data were analyzed using SPSS via $\chi^{2}$ test, and the difference was significant $(p<0.05)$.

RESULTS: The expression of CK 6 was high in cholesteatoma (33.3\%) and low in retro-auricular skin. The expression of CK 16 was high in all samples of cholesteatoma and mostly high in the retro-auricular skin; both expressions were statistically significant $(p<0.05)$.

CONCLUSION: The expression of CK 6 and CK 16 in cholesteatoma was higher than in normal retro-auricular skin.

\section{Introduction}

Chronic suppurative otitis media (CSOM) is a chronic middle ear infection characterized by a history of continuous ear discharge from the middle ear through the perforated tympanic membrane [1], [2], [3]. Secretions in CSOM occur either intermittently or continuously for more than 2 months [4]. Particularly in developing countries, the prevalence of CSOM is 65-330 million people. As per the data of CSOM provided by the World Health Organization, Indonesia belongs to countries with high prevalence, ranging from $2 \%$ to $4 \%$ [2]. According to a national survey of sight and hearing health in Indonesia, the prevalence rate is $3.8 \%$ from 1994 to 1996 [1], [4].

Cholesteatoma is a lesion of the temporal bone lined by a stratified squamous epithelium containing desquamated keratin. The molecular mechanism of the pathogenesis of cholesteatoma formation remains unclear [5], [6], [7]. The incidence of cholesteatoma ranges from nine to ten cases per 100,000 adults and three cases per 100,000 children with a male-to-female ratio of $1.8: 1$ [8].

The etiopathogenesis of cholesteatoma cannot be certainly explained. The mechanisms that underlying cholesteatoma etiopathogenesis remain under study. Four dominant theories, namely, invagination theory, migration, squamous metaplasia, and basal cell hyperplasia, remain under debate. However, no single theory explains the clinical characteristics of cholesteatoma [9], [10], [11].

Cholesteatoma is hyperproliferative because of the response of direct biomechanical trauma, and inflammation processes then lead to temporal bone destruction with some clinical manifestations of complications [5], [11]. The hyperproliferation mechanism occurred because of the activation of intermediate filament protein type I and type II known as cytokeratin (CK) [12], [13]. Keratinocyte in the epidermis will express its CK with its specific function to respond to any inflammation or trauma as a first barrier (defense mechanism) [14], [15]. If biomechanical trauma or any inflammation occurred, the keratinocyte balancing cycle and CK expression will be altered and release inflammatory cytokines [15].

The main role of $\mathrm{CK}$ in keratin differentiation and regeneration is to respond to mechanical and biochemical factors or inflammation processes. CK is classified into type I soft CK (CK 10-20) called the acidic low-molecular-weight keratin and type II hard CK (CK 1-9) called the neutral/basic high-molecularweight keratin [13]. Every epithelial cell will have a CK expression paired with type I and type II to adapt to any type of epithelial cell and its differentiation stages [13], [14], [15]. 
CK activation was divided into two pathways, namely, differentiation (CK 1/10) and regenerative (CK 6/16). In a normal epidermis, keratinocytes will differentiate through the mitotic process in the basal layer and then shift to the squamosal, granular, and corneum layers. Normal differentiation will express CK 5/14 in the basal layer and CK 1/10 in the suprabasal layer [16]. If trauma, chemical irritation, or exposure to pathogen occurred, keratinocyte will activate as an epidermal defense mechanism. This activation was stimulated by growth factors and inflammatory cytokines such as interleukin 1 (IL-1), tumor necrosis factor alpha (TNF- $\alpha$ ), transforming growth factor alpha (TGF- $\alpha$ ), TGF- $\beta$, and interferon gamma (IFN- $\gamma$ ) [13], [14], [15], [16].

When trauma or inflammation occurred, keratinocytes will give an alarmin signal with IL-1 and chemokin. IL-1 has an autocrine/paracrine role; it can initiate activation or act as a paracrine. Thus, IL-1 will change CK 5/14 into CK 6/16 with hyperproliferative and migratory characteristics. Moreover, IL-1 will induce TNF- $\alpha$ and TGF $-\alpha$, which could balance the expression of $\mathrm{CK}$ 6/16 until re-epithelialization was considered complete. At the end of the cycle, the IFN- $\gamma$ was released to expressed CK 17 to make healed keratinocyte contract and form a new one; then, TGF- $\beta$ was released to bring an epithelial cell back into CK 5/14 expression at the basal layer. The whole process was called the normal keratinocyte activation cycle [13], [14], [15], [16].

One etiopathogenesis of cholesteatoma is basal cell hyperplasia, which then leads to the hyperproliferation of the suprabasal cell. Koç and Emre stated in the animal study from Sasaki [17] that there was an increasing expression of CK 16 through immunohistochemistry in cholesteatoma, suprabasal layer, and retro-auricular skin. In Kim's study, there was an increasing expression of CK 13 and CK 16 in the suprabasal layer [18]. Klenke's study also found an increasing expression of CK 6 and CK 14 through immunohistochemistry [19]; moreover, they conduct a real-time polymerase chain reaction (RT-PCR) examination and found an increasing expression of CK 6 in cholesteatoma.

This study was conducted to analyze the expression of CK 6/16 in cholesteatoma patients with CSOM and also to find if it could be one of the management modalities in treating cholesteatoma patients with CSOM. So far, this is the first study about CK conducted in Indonesia.

\section{Materials and Methods}

\section{Study design}

This research is an analytical study that used a comparative cross-sectional design.

\section{Subjects}

The subjects of this study were the biological materials (cholesteatoma as the case and retroauricular skin as the control) of CSOM patients who had undergone tympanomastoidectomy in Dr. M. Djamil Hospital Padang. The inclusion criterion was cholesteatoma tissue that has been confirmed by the Laboratory of Pathology Anatomy, Dr. M. Djamil Hospital Padang, and the exclusion criterion was CSOM type cholesteatoma patient with psoriasis vulgaris of the ear. A total of 15 cases of cholesteatoma as the case and retro-auricular skin as the control were included in the study. The study was approved by the ethics committee of the Faculty of Medicine, Andalas University, Padang, Indonesia (No.012/KEP/FK/2020).

\section{Cholesteatoma isolation}

Cholesteatoma samples were taken from the mastoid cavity, whereas normal ear skin was taken from the retro-auricular skin with a size of $0.5 \mathrm{~cm}$ when tympanomastoidectomy was performed in the operating room. Cholesteatoma collection is included in one of the steps of the tympanomastoidectomy procedure, in which the sample material that was taken is the residual material of the operation that will beexaminedforAnatomicalPathology at the Anatomical Pathology Laboratory. Samples were taken, put into a tube containing formalin, and then were transferred into glass slide and paraffin block and stored at $-80^{\circ} \mathrm{C}$ in the Anatomical Pathology Laboratory of the Faculty of Medicine, Andalas University, Padang.

\section{Immunohistochemistry}

The paraffin blocks were cut, and the samples were adhered to a layered glass of poly-l-lysine, dewaxed for an hour, deparaffinized, rehydrated, and then rinsed with poly buffer saline for 30 min. Primary antibody of CK-6 Monoclonal Antibody, Elabscience E-AB-71048; dilution 1:100 and CK-16 Monoclonal Antibody; Elabscience E-AB-71052; and dilution 1:100 were applied. Add the secondary antibody, and then, coloring with counterstaining hematoxylin follows.

\section{Data collection}

The expression of CK 6/16 was analyzed through immunohistochemistry and scored using the immunoreactivity score (IRS) from the multiplication of proportion score and intensity score, that range from 0 to 3 as the under/low expression and $>4$ as the over/high expression.

\section{Statistical analysis}

All data were processed manually, the quantitative data were analyzed in a computer using 
the SPSS program and presented in a tabular form and then continued using the $\chi^{2}$ test. The difference was statistically significant $(p<0.05)$.

\section{Results}

A total of 15 patients were included in this study, and all the information was compiled and presented in tables. Table 1 shows the characteristics of the samples. In this table, males are more affected (53.3\%) than females $(46.7 \%)$. The male-to-female ratio is $1.4: 1$.

Table 1: Distribution of patients by sex $(n=15)$

\begin{tabular}{lll}
\hline Sex & $f$ & $\%$ \\
\hline Male & 8 & 53.3 \\
Female & 7 & 46.7 \\
\hline
\end{tabular}

Table 2 showed some type of tympanic membrane perforation mostly is in the attic $(46.7 \%)$ of the patients who suffered from clinical symptoms for $11-15$ years $(33.3 \%)$. Furthermore, Table 3 showed that almost all the patients presented with more than one symptom. The most common symptoms include discharge from the ear (100\%) and hearing impairment (100\%), followed by headache and postauricular swelling.

Table 2: Distribution of patients by age $(n=15)$

\begin{tabular}{lll}
\hline Age (years) & $f$ & $\%$ \\
\hline$\leq 10$ & 1 & 7 \\
$>10-20$ & 4 & 27 \\
$>20-30$ & 6 & 40 \\
$>30-40$ & 2 & 13 \\
$>40-50$ & 2 & 13 \\
\hline
\end{tabular}

Table 3: Distribution of patients by symptoms and perforation type $(n=15)$

\begin{tabular}{lll}
\hline Characteristic & $\mathrm{f}$ & $\%$ \\
\hline Symptom & & \\
Discharge from ear & 15 & 100 \\
Hearing impairment & 15 & 100 \\
Vertigo & 1 & 6.7 \\
Facial paralysis & 1 & 6.7 \\
Retro-auricular swelling & 3 & 20 \\
Headache & 5 & 33.3 \\
Seizure & 0 & 0 \\
Decrease of consciousness & 0 & 0 \\
Tympanic membrane perforation type & & \\
Total & 4 & 26.7 \\
Subtotal & 3 & 20 \\
Central & 1 & 6.7 \\
Attic & 7 & 46.7 \\
\hline
\end{tabular}

Table 4 shows the expression of CK 6 between the cholesteatoma group and the retro-auricular skin group. The expression of CK 6 was highly expressed in five cases of cholesteatoma $(33.3 \%)$ and low in ten cases $(66.7 \%)$. In the retro-auricular skin group,

Table 4: Expression of CK 6 in the cholesteatoma and retro-auricular skin groups

\begin{tabular}{|c|c|c|c|c|c|c|c|}
\hline \multirow[t]{3}{*}{ Group } & \multicolumn{4}{|c|}{ CK 6 expression } & \multirow{2}{*}{\multicolumn{2}{|c|}{ Total }} & \multirow[t]{3}{*}{$\mathrm{p}$} \\
\hline & \multicolumn{2}{|c|}{ Low } & \multicolumn{2}{|c|}{ High } & & & \\
\hline & $\bar{f}$ & $\%$ & $f$ & $\%$ & $f$ & $\%$ & \\
\hline Cholesteatoma & 10 & 66.7 & 5 & 33.3 & 15 & 100 & 0.042 \\
\hline Retro-auricular skin & 15 & 100 & 0 & 0 & 15 & 100 & \\
\hline
\end{tabular}

CK 6 was low in all samples. This CK 6 expression is statistically significant $(p<0.05)$ (Figure 1).

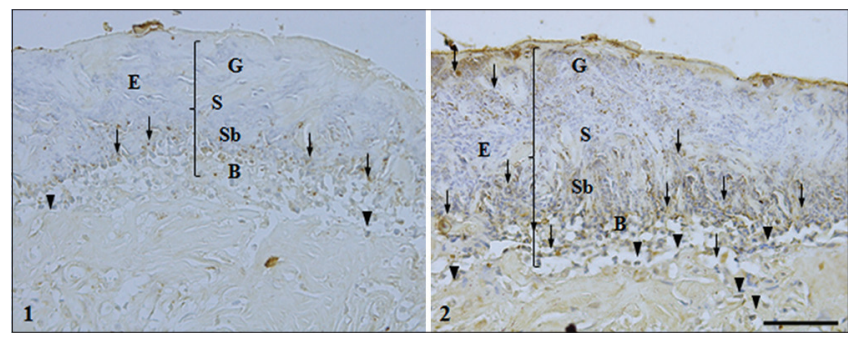

Figure 1: Cytokeratin (CK) 6 expression in retro-auricular skin (1) and in cholesteatoma (2). CK 6 was expressed as brown in stain in epithelial cytoplasm (arrow) in basal (b) and suprabasal (Sb). The expression of CK 6 was higher in cholesteatoma with partial expression of the epithelium spinosum (s) and granulosum (g). Epithelial cholesteatoma appears with proliferative signs (high epithelial thickness). The stroma below the dermis contains connective tissue with medium term lymphocytes and PMN leukocytes (arrowheads). Immunoperoxidase, obj 40x, scale $200 \mu \mathrm{m}$

Table 5 shows the expression of CK 16 between the cholesteatoma group and the retroauricular skin group. The expression of CK 16 was highly expressed in 15 cases of cholesteatoma $(100 \%)$. In the retro-auricular skin group, CK 16 expression was high in ten cases $(66.7 \%)$ but low in five cases (33.3\%) of cholesteatoma. This CK 16 expression is statistically significant $(p<0.05)$.

Table 5: Expression of CK 16 in the cholesteatoma and retro-auricular skin groups

\begin{tabular}{|c|c|c|c|c|c|c|c|}
\hline \multirow[t]{3}{*}{ Group } & \multicolumn{4}{|c|}{ CK 16 expression } & \multirow{2}{*}{\multicolumn{2}{|c|}{ Total }} & \multirow[t]{3}{*}{$p$} \\
\hline & \multicolumn{2}{|c|}{ Low } & \multicolumn{2}{|c|}{ High } & & & \\
\hline & $f$ & $\%$ & $f$ & $\%$ & $f$ & $\%$ & \\
\hline Cholesteatoma & 0 & 0 & 15 & 100 & 15 & 100 & 0.042 \\
\hline Retro-auricular skin & 5 & 33.3 & 10 & 66.7 & 15 & 100 & \\
\hline
\end{tabular}

Table 6 presents the distribution expression of CK 6 and CK 16 between the cholesteatoma group and the retro-auricular skin group. The distribution expression of CK 6 was mostly in the basal layer in cholesteatoma, whereas in retro-auricular skin, all samples were expressed in the basal layer (Figure 1). Conversely, all samples of cholesteatoma were expressing CK 16 in the suprabasal layer, whereas most of the retro-auricular skin (66.7\%) was expressed in the basal layer (Figure 2).

Table 6: Distribution expression of CK 6/16 in the cholesteatoma and retro-auricular skin groups

\begin{tabular}{|c|c|c|c|c|c|c|}
\hline \multirow[t]{4}{*}{ Cytokeratin } & \multicolumn{6}{|c|}{ Group } \\
\hline & \multicolumn{4}{|c|}{ Layer } & \multicolumn{2}{|c|}{ Total } \\
\hline & \multicolumn{2}{|c|}{ Suprabasal } & \multicolumn{2}{|c|}{ Basal } & \multirow[b]{2}{*}{$f$} & \multirow[b]{2}{*}{$\%$} \\
\hline & $f$ & $\%$ & $f$ & $\%$ & & \\
\hline \multicolumn{7}{|l|}{ CK 6} \\
\hline Cholesteatoma & 5 & 33.3 & 10 & 66.7 & 15 & 100 \\
\hline Retro-auricular skin & 0 & 0 & 15 & 100 & 15 & 100 \\
\hline \multicolumn{7}{|l|}{ CK 16} \\
\hline Cholesteatoma & 15 & 100 & 0 & 0 & 15 & 100 \\
\hline Retro-auricular skin & 5 & 33.3 & 10 & 66.7 & 15 & 100 \\
\hline
\end{tabular}

\section{Discussion}

Several studies regarding the expression of CK 6 and CK 16 against cholesteatoma had been 


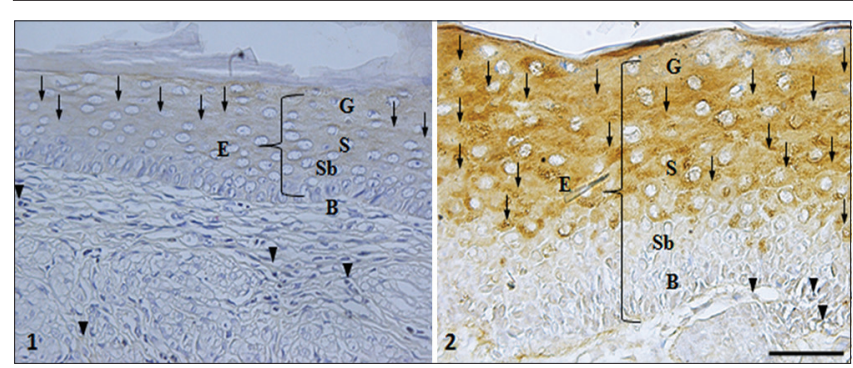

Figure 2: Cytokeratin (CK) 16 expression in retroauricula skin (1) and in cholesteatoma (2). CK 16 was expressed as brown in stain in epithelial cytoplasm (arrow) in basal (b) and suprabasal (Sb). The expression of CK 16 appeared to be higher in cholesteatoma with a higher proportion and intensity of staining. There was also cholesteatoma epithelium with proliferative signs (high epithelia thickness) and a large portion of the epithelium, especially the upper layer. The stroma beneath the dermis contains connective tissue with medium term lymphocyte cells and PMN leukocytes. (arrowheads). Immunoperoxidase, obj 40×, scale $200 \mu \mathrm{m}$

published. Maniu et al. [6] stated that CK 6 and CK 16 are known as intermediate filamentous proteins derived from the epithelium as markers of keratinocyte proliferation. Maniu et al. [6] also stated that the cholesteatoma matrix expresses large amounts of CK 16 in the suprabasal layer. Moreover, Olszweska et al. [20] stated that there was an increase in hyperproliferative expression in CK 6, CK 16, and CK 19 in cholesteatoma epithelium on immunohistochemical examination, especially in the suprabasal layer.

In cholesteatoma, proliferative activity occurs in the basal layer with a large number of cells (hyperplasia) and additional proliferative activity in the suprabasal layer [14], [15], [16], [17], [18], [19]. In normal epithelium, keratinocytes undergo a slow proliferation process in the basal layer and differentiation in the suprabasal layer. Based on the CK activation cycle, if there is inflammation or injury, the proliferation and differentiation cycle will take place very rapidly as a regenerative response induced by $\mathrm{IL}-1$. IL-1 will activate the keratinocyte regenerative pathway, that is, the activation of CK 6 and CK 16 to initiate the proliferative and migration process. CK 6 is migratory, whereas CK 16 is hyperproliferating. Both of these CK expressions are simultaneously regulated by TNF- $\alpha$ (as a signal of inflammation) and TGF- $\alpha$ (as a signal of proliferation). However, in cholesteatoma due to chronic inflammation and continuous mechanical trauma from the accumulated cholesteatoma debris, the induced IL-1 resulted in an imbalance of the regenerative activation pathways of CK 6 and CK 16 and an imbalance of the action of TNF- $\alpha$ and TGF- $\alpha$ Hence, normal CK loses its balancing ability between proliferation and differentiation to the corneum layer due to chronic inflammation and continuous mechanical trauma from cholesteatoma and shifting to surface layer pattern that results in immature differentiation of keratinocytes in the suprabasal layer due to different differentiation rates from the normal epithelium [16], [20]. However, until now the authors have not found any studies linking IL-1 or TNF- $\alpha$ and TGF- $\alpha$ directly to CK 6 and
CK 16 in cholesteatoma. Several studies that have been described are differences in TNF- $\alpha$ expression in cholesteatoma with RT-PCR techniques, such as in the study of Swanda et al. [21] who stated that there was an increase in TNF- $\alpha$ by 36 times in cholesteatoma.

It can explain that, in this study, five samples $(33.3 \%)$ of the high CK 6 expression were found in the suprabasal layer of cholesteatoma as a result of CK 6 migratory activity as a response to chronic inflammation of CSOM (Figure 1). Meanwhile, ten other cholesteatoma samples $(66.7 \%)$ expressed weakly and were found in the basal layer. This was also found in the study of Hamed et al. [10] in which 15 samples of cholesteatoma and six samples of ear skin with immunohistochemistry were involved. It was found that CK 5 and CK 6 were expressed in cholesteatoma epithelium and normal ear skin, but there was no statistically significant difference in the staining intensity $(p>0.05)$. CK 6 expression is weak in cholesteatoma and found in the basal layer (Figure 1). It could be caused by variations in the expression of CK and the thickness of the epithelium of each individual; also, the number of samples used was still said to be minimal. The dysregulation of the CK cycle also causes the speed of differentiation to become irregular, resulting in the expression of $\mathrm{CK} 6$ still in the basal layer, although it is weak. Kim et al. [22] cited a statement from Anniko's study stating that the epithelium varies greatly in each individual, not only in people with cholesteatoma but also in other epithelial tissue layers. Hence, the results of this study are sufficient to explain the theory which states that in cholesteatoma a process of basal cell hyperplasia and hyperproliferation occurs in suprabasal cells, which are different from the growth or differentiation of normal epithelial cells.

In this study, CK 16 was more significantly expressed in cholesteatoma than CK 6 (Figure 2). High CK 16 expression was obtained in all cholesteatoma samples (100\%), whereas CK 6 was highly expressed in five cholesteatoma samples $(33.3 \%)$. This is believed to be related to the types of CK expressed: type I (10-20, acidic) and type II (1-9, base/neutral). The theory of acidity in cholesteatoma has been proposed by Nguyen et al. [23] who obtained an acidic $\mathrm{pH}$ of cholesteatoma keratin debris with a mean $\mathrm{pH}$ of $6.65+0.07$. According to his study, it was concluded that the accumulation of cholesteatoma keratin debris would cause high acidity in cholesteatoma, further causing bone destruction due to the suppression of keratin debris and the effect of this acidity. Based on the Nguyen et al. [23] found highly expressed CK 16 is closely related to the high acidity of cholesteatoma, which is also associated with the risk of bone destruction later [23]. Thus, it can explain why CK 16 is more clearly expressed in cholesteatoma than CK 6.

Kim et al. [22] conducted an experimental study of experimental animals that were given three treatments (closure of the external acoustic canal, 
retraction pocket, and the administration of propylene glycol) to develop cholesteatoma; it was found that the increase in CK 16 was very prominent in the suprabasal layer of the cholesteatoma epithelium in the retraction pocket group (with the unilateral cauterization of the left Eustachian tube). In the suprabasal layer of ear skin, CK 16 expression was also found, but it was not as strong as the expression in the cholesteatoma epithelium (Figure 2). CK 16 which is strongly expressed in the suprabasal layer is the result of hyperproliferation that is not balanced with the re-epithelialization process. In the expression of CK 6, there was a significant increase in the external acoustic canal closure group compared with that in the others. Based on the overall study, it was concluded that CK 6, which was strongly expressed in the external acoustic canal closure group, supported the theory of basal cell hyperplasia in cholesteatoma and strong CK 16 expression in the retraction pocket group supported the invagination and migration theory in the pathogenesis of cholesteatoma. If it is related to the characteristics of the sample, almost half $(46 \%)$ appeared with a perforation type that, based on the theory of cholesteatoma formation, can arise due to the process of invagination theory and migration theory.

The previous studies stated that there were differences in the expression of CK 6 and CK 16 between cholesteatoma and retro-auricular skin. These studies used different examination methods, such as RT-PCR, microarray, and IHK. In this study, the examination method used was an immunohistochemistry examination, in which the analysis used was the IRS system. IHK examination with IRS analysis is a type of $\mathrm{CPI}$ analysis that is widely used and can assess from the intensity level, the proportion in the cytoplasm, to the cell nucleus [24].

\section{Conclusion}

Our study reveals that CK 6/16 was highly expressed in cholesteatoma compared with that in controls, and there is a statistically significant difference. Further studies are still warranted to elaborate on the role of $\mathrm{CK} 6 / 16$, as well as its correlation with $\mathrm{IL}-1$ and TNF- $\alpha$ in cholesteatoma.

\section{Acknowledgment}

The authors thank to Otorhinolaryngology Department Faculty of Medicine, Andalas University, Faculty of Biomedics Andalas University and Laboratory of Pathology Anatomy Dr. M. Djamil Hospital Padang, West Sumatera, Indonesia for supporting this research.

\section{References}

1. World Health Organization. Chronic Suppurative Otitis Media: Burden of Illness and Management Options. Geneva: World Health Organization; 2004. Available from: https://apps.who.int/ iris/handle/10665/42941 [Last accessed on 2021 May 17].

2. Utami TF, Sudarman K, Rianto BU, Christanto A. Rinitis Alergi sebagai Faktor Risiko Otitis Media Supuratif Kronis [Allergic Rhinitis as a Risk Factor for Chronic Suppurative Otitis Media]. Cermin Dunia Kedokt. 2010;179:425-9.

3. Darmawan $A B$, Anjarwati DU. Perbedaan sensitivitas tetes telinga antibiotik terhadap Pseudomonas aeruginosa pada otitis media supuratif kronik [Differences in the sensitivity of antibiotic ear drops to Pseudomonas aeruginosa in chronic suppurative otitis media]. Oto Rhino Laryngol Indones. 2012;42(2):77-82. https://doi.org/10.32637/orli.v42i2.22

4. Helmi. Otitis Media Supuratif Kronis [Chronic Suppurative Otitis Media]. In: Otitis Media Supuratif Kronis Pengetahuan Dasar Terapi Medik Mastoidektomi Timpanoplasti [Chronic Suppurative Otitis Media Basic Knowledge of Medical Therapy Mastoidectomy Tympanoplasty]. Jakarta: Balai Penerbit FKUI; 2005.

5. Likus W, Siemianowicz K, Markowski J, Wiaderkiewicz J, Kostrząb-Zdebel A, Jura-Szołtys E, et al. Bacterial infections and osteoclastogenesis regulators in men and women with cholesteatoma. Arch Immunol Ther Exp (Warsz) 2016;64(3):241-7. https://doi.org/10.1007/s00005-015-0373-7

6. Maniu A, Harabagiu $O$, Schrepler MP, Cătană A, Fănuţă $B$, Mogoantă CA. Molecular biology of cholesteatoma. Rom $J$ Morphol Embryol. 2014;55(1):7-13.

7. de Aquino JE, Filho NA, de Aquino JN. Epidemiology of middle ear and mastoid cholesteatomas: Study of1146 cases. Braz J Otorhinolaryngol. 2011;77(3):341-7. https://doi.org/10.1590/ S1808-86942011000300012

8. Jackler RK, Maria PL, Varsak YK, Nguyen A, Blevin NH. A new theory on the pathogenesis of acquired cholesteatoma: Mucosal traction. Laryngoscope. 2015;125(Suppl 4):S1-14. https://doi. org/10.1002/lary.25261

9. Kuo CL, Shiao AS, Yung M, Sakagami M, Sudhoff $\mathrm{H}$, Wang $\mathrm{CH}$, et al. Updates and knowledge gaps in cholesteatoma research. Biomed Res Int. 2015;2015:854024. https://doi. org/10.1155/2015/854024

10. Hamed MA, Nakata S, Sayed RH, Ueda H, Badawy BS, Nishimura $Y$, et al. Pathogenesis and bone resorption in acquired cholesteatoma: Current knowledge and future prospectives. Clin Exp Otorhinolaryngol. 2016;9(4):298-308. https://dx.doi. org/10.21053\%2Fceo.2015.01662

11. Pivarcsi A, Müller A, Hippe A, Rieker J, van Lierop $A$, Steinhoff $M$, et al. Tumor immune escape by the loss of homeostatic chemokine expression. Proc Natl Acad Sci. 2007;104(48):19055-60.

12. Duan L, Chen $\mathrm{H}$, Gao J. The cytoskeleton of the system. Lab Cell Biol Technic 2017;1(1):17-22

13. DePianto D, Coulombe PA. Intermediate filaments and tissue repair. Exp Cell Res 2004;301(1):68-76. https://doi. org/10.1016/j.yexcr.2004.08.007

14. Lessard JC, Pina-Paz S, Rotty JD, Hickerson RP, Kaspar RL, Balmainet $A$, et al. Keratin 16 regulates innate immunity in response to epidermal barrier breach. Proc Natl Acad Sci. $\quad$ 2013;110(48):19537-42. https://doi.org/10.1073/ pnas. 1309576110

PMid:24218583

15. Juráňová J, Franková J, Ulrichová J. The role of keratinocytes in inflammation. J Appl Biomed. 2017;15(3):169-79. https://doi. org/10.1016/j.jab.2017.05.003 
16. Freedberg IM, Tomic-Canic $M$, Komine $M$, Blumenberg $M$. Keratins and the keratinocyte activation cycle. J Invest Dermatol 2001;116(5):633-40.

https://doi.org/10.1046/j.1523-1747.2001.01327.x

PMid:11348449

17. Koç A, Emre E. An overview to cytokeratin pattern. ACU Sağlık Bil Derg 2015;6(1):1-6.

18. Kim HJ, Tinling SP, Chole RA. Expression patterns of cytokeratins in retraction pocket cholesteatomas. Laryngoscope. 2009;111(6):1032-6.

https://doi.org/10.1097/00005537-200106000-00018

19. Klenke C, Janowski S, Borck D, Widera D, Ebmeyer J, Kalinowski J, et al. Identification of novel cholesteatoma-related gene expression signatures using full-genome microarrays. PLoS One. 2012;7(12):e52718. https://doi.org/10.1371/journal. pone.0052718

20. Olszewska E, Wagner M, Bernal-Sprekelsen M, Ebmeyer J, Dazert S, Hildmann $\mathrm{H}$, et al. Etiopathogenesis of cholesteatoma. Eur Arch Otorhinolaryngol 2004;261(1):6-24. https://doi. org/10.1007/s00405-003-0623-x
21. Swanda D, Edward Y, Munilson J. Ekspresi Tumor Necrosis Factor dan Interleukin-6 Pada Kolesteatoma Penderita Otitis Media Supuratif Kronis [Expression of Tumor Necrosis Factor and Interleukin-6 in Cholesteatoma in Chronic Suppurative Media Otitis Patients]. Padang: Master Thesis, Andalas University; 2017. p. 37-9.

22. Kim HJ, Tinling SP, Chole RA. Increased proliferation and migration of epithelium in advancing experimental cholesteatomas. Otol Neurotol. 2002;23(6):840-4. https://doi. org/10.1097/00129492-200211000-00005

PMid: 12438843

23. Nguyen $\mathrm{KH}$, Suzuki $\mathrm{H}$, Ohbuchi T, Wakasugi T, Koizumi $\mathrm{H}$ Hashida $\mathrm{K}$, et al. Possible participation of acidic $\mathrm{pH}$ in bone resorption in middle ear cholesteatoma. Laryngoscope. 2014;124(1):245-50. https://doi.org/10.1002/lary.23883 PMid:24122656

24. Fedchenko N, Reifenrath J. Different approaches for interpretation and reporting of immunohistochemistry analysis results in the bone tissue a review. Diagn Pathol. 2014;9:221. https://doi.org/10.1186/s13000-014-0221-9

PMid:25432701 